A-riviog

Free to Authors and Readers
A Platinum Open Access Journal for Organic Chemistry
Paper

Arkivoc 2021, part viii, 296-309

\title{
Synthesis, anticancer activity and molecular docking studies of new 4- nitroimidazole derivatives
}

\author{
Yaseen A. Al-Soud, ${ }^{a^{*}}$ Kafa' A. S. Alhelal, ${ }^{\text {a }}$ Bahjat A. Saeed, ${ }^{b}$ Luay Abu-Qatouseh, ${ }^{c}$ Hossam H. Al-Suod, ${ }^{a}$ Ala'a \\ H. Al-Ahmad, ${ }^{a}$ Najim A. Al-Masoudi, ${ }^{\text {* }}$ and Raed A. Al-Qawasmeh ${ }^{\mathrm{e}}$ \\ ${ }^{a}$ Chemistry Department, Faculty of Science, University of Al al-Bayt, Al-Mafraq, Jordan \\ ${ }^{b}$ Department of Chemistry, College of Education for Pure Science, University of Basrah, Basrah, 61001 Iraq \\ ${ }^{c}$ Faculty of Pharmacy, University of Petra, Amman, Jordan \\ ${ }^{d}$ Department of Chemistry, College of Science, University of Basrah, Basrah, 61001 Iraq, \\ Present address: Konstanz, 78464 Germany \\ ${ }^{e}$ Department of Chemistry, College of Sciences, University of Sharjah, Sharjah 27272, UAE; and Department of \\ Chemistry, The University of Jordan, Amman 11942, Jordan \\ Email: alsoud@aabu.edu.jo, najim.al-masoudi@gmx.de
}

Received 01-24-2021

Accepted 07-08-2021

Published on line $07-16-2021$

\section{Abstract}

Imidazoles have occupied a unique position in heterocyclic chemistry, and its derivatives have attracted considerable interests in recent years for their versatile properties in chemistry and pharmacology. Herein, we report the synthesis of 3-(1-benzyl-2-ethyl-4-nitro-1H-imidazol-5-ylsulfanyl)-1-(4-substituted phenyl-piperazin1-yl)-propan-1-one 5a-p by reaction of 3-(1-benzyl-2-methyl-4-nitro-1H-imidazol-5-ylsulfanyl)-propanoyl chloride (3) with piperazine nucleophiles. Eighteen compounds were assessed for their antiproliferative inhibition potency against four human cancer cell lines (MCF-7, PC3, MDA MB231 and Du145). Compounds 5f and $\mathbf{5 k}$ were the most potent anticancer agents on MCF-7 cell lines cell line with $\mathrm{IC}_{50}$ value of $1.0 \mu \mathrm{g} / \mathrm{mL}$, while $\mathbf{5 d}$ and $\mathbf{5 m}$ exhibited cytotoxic effect on PC3 and DU145 cell lines with $\mathrm{IC}_{50}$ values of 4.0 and $5.0 \mu \mathrm{g} / \mathrm{mL}$, respectively. The molecular docking of compounds $\mathbf{5 f}, \mathbf{5} \mathrm{d}$ and $\mathbf{5 m}$ has been studied.

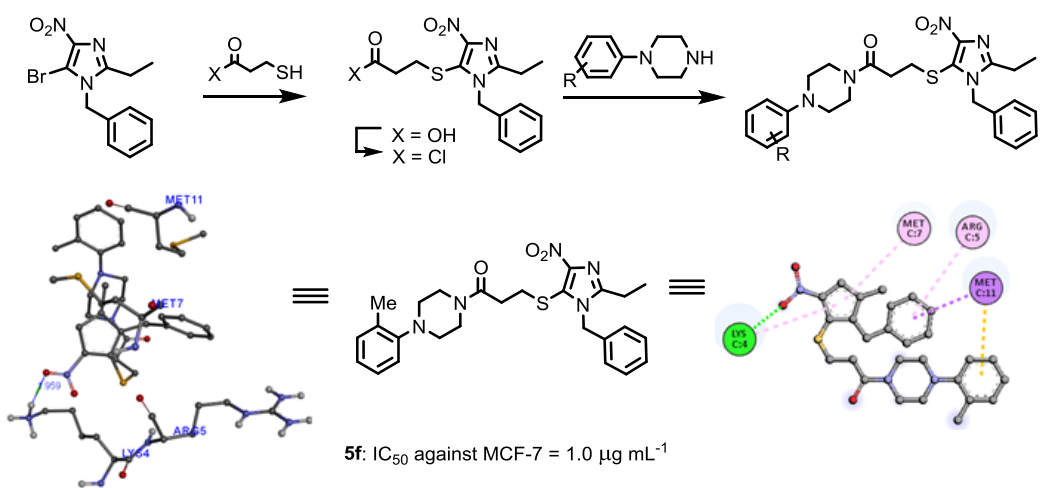

Keywords: Anticancer activity, imidazoles, piperazines, molecular docking study 


\section{Introduction}

Imidazoles have attracted attention since imidazole ring presents in the essential amino acid, histidine which is existed in many proteins and enzymes and plays an important role in the structure and binding function of hemoglobin. Biological studies showed great numbers of substituted imidazoles with wide spectrum of biological activities, such as antitumor, antimicrobial, anti-HIV, antibacterial, antihypertensive, antifungal and anticonvulsant activity. ${ }^{1-6}$ Imidazole nucleus and its derivatives are considered as privileged scaffold in medicinal chemistry, they constitute an important class of therapeutic agents and well known as drugs. For example; Dacarbazine (DTIC) (5-(3,3-dimethyl-1-triazeno)imidazol-4-carboxamide was synthesized as an alkylating agent ${ }^{7}$ and used in the treatment of metastatic melanoma ${ }^{8,9}$ as well as a part of the ABVD chemotherapy regimen to treat Hodgkin's lymphoma ${ }^{10,11}$ and in the MAID regimen for sarcoma. ${ }^{12}$ Temozolomide (Temodar) is also classified as one of alkylating agents commonly used to treat certain types of brain tumors such as glioblastoma multiforme or anaplastic astrocytoma. ${ }^{13,14}$ Furthermore, clotrimazole [1-(2chlorotrityl)- $1 \mathrm{H}$-imidazole] is an azole antimycotic agent (antifungal) and used to treat skin infections such as athlete's foot, jock itch, ringworm, and other fungal skin infections (candidiasis). ${ }^{15,16}$ Moreover, imidazole ring substituted with nitro group (nitroimidazoles) are also biologically active compounds commonly used as therapeutic agents for treatment of different diseases such as; metronidazole [2-(2-methyl-5-nitroimidazol-1$\mathrm{yl}$ )ethanol] (Flagyl) (antibiotic) is used to treat trichomoniasis, amoebiasis, and giardiasis. ${ }^{17}$ Misonidazole (1methoxy-3-(2-nitroimidazol-1-yl)propan-2-ol) (radiosensitizer and antineoplastic) is one of the imidazole drugs which used for treatment of hypoxic tumors, ${ }^{18}$ meanwhile cimetidine is considered as a potential histamine $\mathrm{H} 2$ receptor antagonist that inhibits stomach acid production. ${ }^{19}$ In addition, secnidazole (hydroxy-2-propyl)-Imethyl-2-nitro-5-imidazole) and tinidazole (1-[2-(ethylsulfonyl)ethyl]-2-methyl-5-nitroimidazole) has been described for treatment of bacterial vaginosis. ${ }^{20,21}$ Some selected structures of biologically active imidazole compounds are shown in Figure 1.

Based on the imidazole pharmacological importance of imidazole derivatives and in contituation of our previous work on imidazole analogues with their antiviral and anticancer activity, ${ }^{22-29}$ we report here new derivatives of nitroimidazole-containing piperazine derivatives and evaluation of their anticancer activity as well as the molecular docking study.
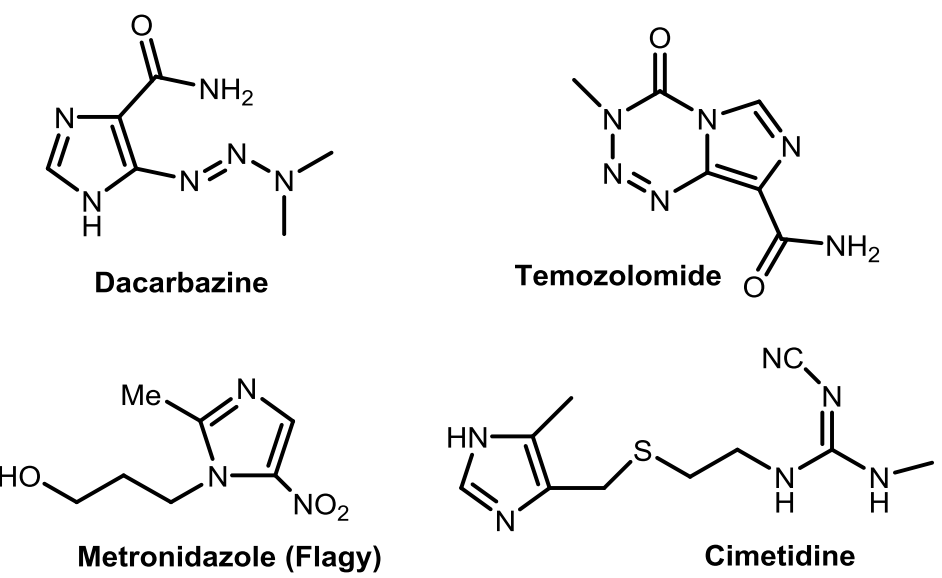

Figure 1. Some biologically active imidazole compounds. 


\section{Results and Discussion}

\section{Chemistry}

Over the last fifteen years, our laboratory synthesized several new derivatives of 4-nitroimidazoles, including some new 5-alkylsulfanyl derivatives of imidazoles ${ }^{27}$ via the nucleophilic displacements of the bromine atom activated by an adjacent nitro group. Our efforts are continued in preparation of such compounds carrying various potential groups aiming to evaluate their anticancer activity might leading to active candidates.

Compound 1 has been selected as a key intermediate for the synthesis of our targets by treatment with 3-mercaptopropanoic in the presence of $\mathrm{K}_{2} \mathrm{CO}_{3}$ in hot $i$-PrOH to give, after purification, 4 in $60 \%$ yield. The structure assignment of $\mathbf{4}$ follows from the ${ }^{1} \mathrm{H}$ - and ${ }^{13} \mathrm{C}-\mathrm{NMR}$ spectra, and was confirmed by X-ray diffraction. ${ }^{30}$ The crude product of 3-(1-benzyl-2-ethyl-4-nitro- $1 \mathrm{H}$-imidazol-5-ylsulfanyl)propionyl chloride (5), prepared by treatment of $\mathbf{4}$ with excess thionyl chloride, was used directly for the next step without further purification. Substituted-piperazine nucleophiles were treated with 4 to furnish the target products $5 a-r$ in $68-77 \%$ yield. (Scheme 1).<smiles>CCc1nc([N+](=O)[O-])c(Br)n1Cc1ccccc1</smiles>

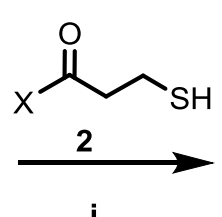

i<smiles>[X]C(=O)CCSc1c([N+](=O)[O-])nc(CC)n1Cc1ccccc1</smiles><smiles>[R]c1ccccc1N1CCN(C(=O)CCSc2c([N+](=O)[O-])nc(CC)n2Cc2ccccc2)CC1</smiles>

\begin{tabular}{l|ll|l}
5 & $R$ & 5 & $R$ \\
\hline $\mathrm{a}$ & $\mathrm{H}$ & $\mathrm{i}$ & $3-\mathrm{MeO}$ \\
$\mathrm{b}$ & $2-\mathrm{F}$ & $\mathrm{j}$ & $4-\mathrm{MeO}$ \\
$\mathrm{c}$ & $4-\mathrm{F}$ & $\mathrm{k}$ & $2-\mathrm{OH}$ \\
$\mathrm{d}$ & $4-\mathrm{Cl}$ & $\mathrm{I}$ & $4-\mathrm{OH}$ \\
$\mathrm{e}$ & $4-\mathrm{Br}$ & $\mathrm{m}$ & $2-\mathrm{CN}$ \\
$\mathrm{f}$ & $2-\mathrm{Me}$ & $\mathrm{n}$ & $4-\mathrm{CN}^{-}$ \\
$\mathrm{g}$ & $3-\mathrm{Me}$ & $\mathrm{o}$ & $4-\mathrm{NO}_{2}$ \\
h & $2-\mathrm{MeO}$ & $\mathrm{p}$ & $4-\mathrm{COCH}_{3}$
\end{tabular}

Scheme 1. Reagents and conditions: (i). $\mathrm{KOH}$, isopropanol, 60-80 oC, 4 h; ii.SOCl2, reflux, 3 h; (iii) substituted piperazine, $\mathrm{CHCl} 3$, pyridine, $\mathrm{rt}, 18 \mathrm{~h}$.

Analogously, aliphatic residues derived piperazine moiety of 5-nitroimidazole analog have prepared, aiming to study the effect of such group on the cancer cell lines. Thus, compounds $\mathbf{5 q}$ and $\mathbf{5 r}$ have been prepared in 75 and $71 \%$ yield, respectively, from 4 using the same procedure described for $5 a-5 p$. (Scheme 2). 

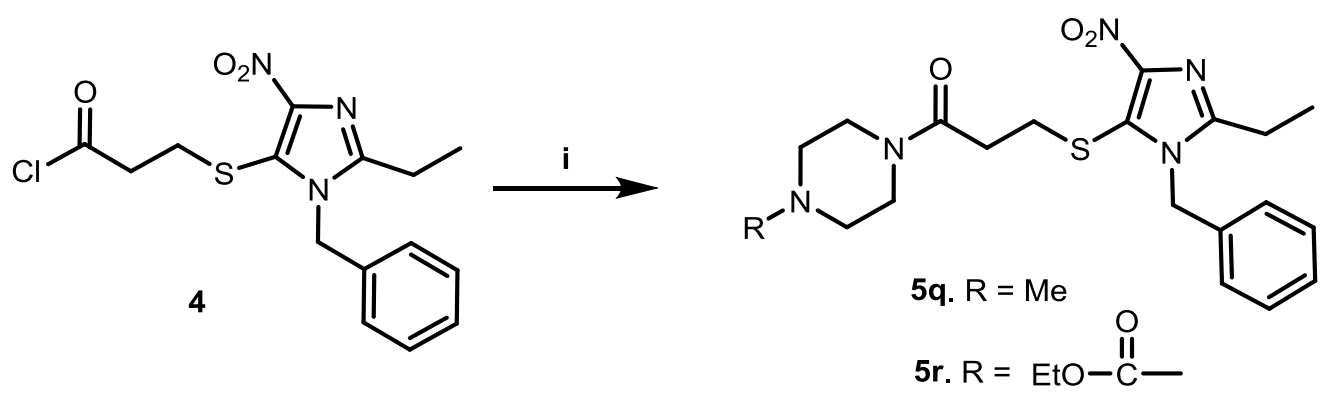

Scheme 2. Reagents and conditions: (i) substituted piperazine, $\mathrm{CHCl} 3$, pyridine, $\mathrm{rt}, 18 \mathrm{~h}$.

The structures of the newly prepared compounds $5 a-5 p$ were confirmed on the basis of their ${ }^{1} \mathrm{H},{ }^{13} \mathrm{C}$ NMR, DEPT experiments (for distinguishing between $\mathrm{CH}_{3}, \mathrm{CH}_{2}, \mathrm{CH}$ carbons and the quaternary carbons) and mass spectroscopic data in addition to elemental analysis. In the ${ }^{1} \mathrm{H}$ NMR spectra, the phenyl, and ethyl protons of the imidazole ring showed rather similar patterns, whereas the singlets in the region $\delta 5.40-5.43$ ppm were attributed to the methylene of benzyl group. The $\mathrm{COCH}_{2} \mathrm{CH}_{2} \mathrm{~S}$ protons appeared in the region $\delta$ 2.63-3.20 ppm. The eight methylene protons of the piperazine ring are equivalent, while the ring protons appear as a broad hump. In the ${ }^{13} \mathrm{C}$ NMR spectra of 5a-5p, resonances in the region $\delta$ 31.3-31.9 ppm were assigned to $\mathrm{SCH}_{2}$ carbon atoms, whereas the signals at $\delta 32.3-32.7 \mathrm{ppm}$ were attributed to the methylene carbons adjacent to the carbonyl group of the amide residue. The $\mathrm{PhCH}_{2}$ carbon atom appeared in the region $\delta$ 47.0-51.4 ppm, while the downfield resonances at the region $\delta$ 168.5-168.9 ppm were assigned to the carbonyl group. Carbon atoms of the imidazole and piperazine moieties have been fully analyzed (c.f. Experimental section).

Additional support for identification of the synthesized compounds came from LC-MS and LC-MS/MS, which revealed the correct molecular ion $[\mathrm{M}+\mathrm{H}]^{+}$, as suggested by their molecular formulas.

\section{In vitro cytotoxic activity}

The cytotoxic potential of the newly synthesized hybrid compounds $\mathbf{5 a - 5} r$ was evaluated in vitro against a panel of human tumor cell lines using MTT assay. ${ }^{31}$ The panel consisted of breast canrcinoma (MCF-7 and MDA MB231), and human prostate cancer (PC-3, and DU-145) cell lines. Paclitaxil and docitaxil were used as the reference drugs. The results are summarized in Table 1, which showed that nitroimidazole scaffold bearing substituted-piperazine moieties have a significant effect on the cytotoxixic activity. Compounds $\mathbf{5 f}$, and $\mathbf{5 k}$ showed a good activity cytotoxic activity against MCF-7 cell lines with $I C_{50}$ values of $1.0 \mu \mathrm{g} / \mathrm{mL}$. $I_{50}$ values of the other analogues against MCF-7 cell lines were ranged between 2.0-8.0 $\mu \mathrm{g} / \mathrm{mL}$, except compounds $5 \mathrm{~g}, \mathbf{5 j}, \mathbf{5 0}$, $\mathbf{5 q}$ and $\mathbf{5 r}$ with $\mathrm{IC}_{50}$ value of $>100 \mu \mathrm{g} / \mathrm{mL}$. In terms of the substituents with different positions of phenylpiperazine residue, the $\mathrm{IC}_{50}$ values of Table 1 clearly showed that the replacement of the $\mathrm{H}$ atom of the phenylpiperazine with 2-Me or 2-OMe groups produced a significant increase in the inhibitory growth effect on the MCF-7 cell lines (compounds $\mathbf{5} \mathbf{f}$ and $\mathbf{5 h}$ ). On the other hand, the synthesized compounds were inactive against breast cancer (MDA MB231 cell lines), except 5k and 5m which exhibited IC 50 values of 12.02 and $10.83 \mu \mathrm{g} / \mathrm{mL}$. Additionally, compounds $\mathbf{5 d}$ and $\mathbf{5 m}$ having the chlorine and cyano groups 4 - and 2-position of the phenylpiperazine ring, respectively, exhibited moderate cytotoxic effect on PCa (PC3 and Du145) cell lines with IC 50 values of 4.0 and $5.0 \mu \mathrm{g} / \mathrm{mL}$, respectively. Figure 2 demonstrates the cell viability (\%) of cell lines, MCF-7, MDA, PC3 and DU145, against compounds 5d, $\mathbf{5 f}$ and $\mathbf{5 m}$. 

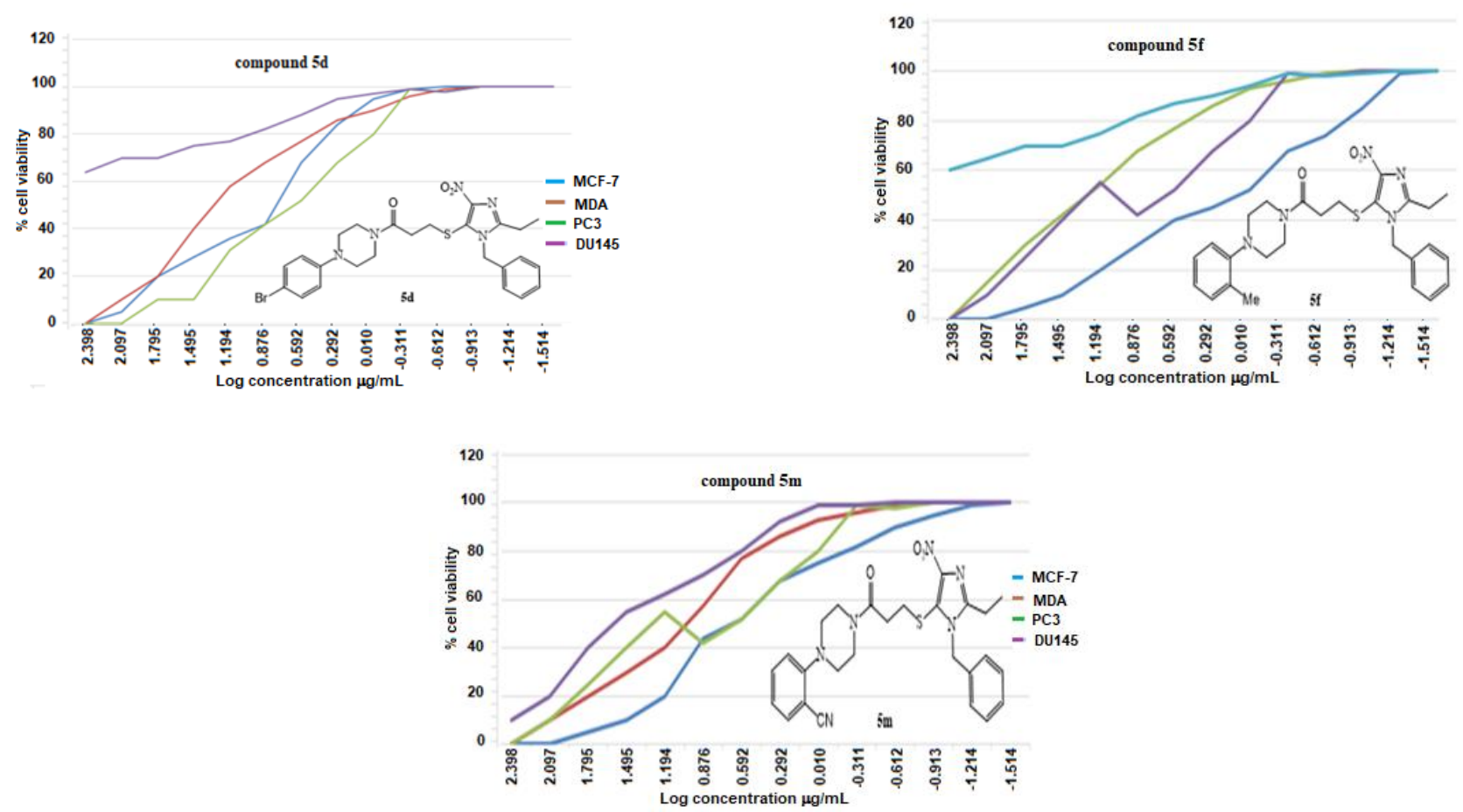

Figure 3. Cell viability \% of cell lines (MCF-7, MDA, PC3 and DU145) against compounds $\mathbf{5 d}, \mathbf{5 f}$ and $\mathbf{5 m}$.

\section{Molecular docking study}

In silico study using molecular docking was undertaken against targets of imidazol analogues to verify the potential affinity of the most active compounds of the series $\mathbf{5 d}, \mathbf{5 f}$ and $\mathbf{5 m}$ to the target proteins. In docking calculations, compound $\mathbf{5} \mathbf{d}$ was docked to the binding pockets of proteins with PDB code 3RUK (chain A), while $5 \mathrm{f}$ and $\mathbf{5 m}$ were docked with 3U2B (B chain) and 5T8E (C chain), respectively, using Autodock $4^{32}$ and the docking results were viewed and analysed by MGLTools.

MCF-7, PC-3 and DU145 cell lines, respectively. The binding energy scores of $\mathbf{5 d}, \mathbf{5} \mathbf{f}$ and $\mathbf{5} \boldsymbol{f}$ were found $-\mathbf{9 . 9 7}$, 7.68 and $-7.17 \mathrm{kcal} \mathrm{mol}^{-1}$, respectively, indicating selectivity and potency profiles of these analogs to bind the active site of proteins pockets. Detailed analysis of the binding mode showed that compound $\mathbf{5 d}$ is settled down in the protein active site properly. Figure. $2(A)$ demonstrated $\pi-\pi$ stacking interactions between the aromatic ring (ring $B$ ) of $\mathbf{5 d}$ and Phe114, together with the same interaction between the pyrrole ring of HEM600 and imidazole scaffold (ring A). Additionally, it showed seven $\pi-H$ interactions: three interactions between the aromatic ring at N-1 (ring B) and Ala367, Val482 and 371 were observed, while other interactions were indicated between imidazole ring and Ala113 and Ala302. Furthermore, $\pi-\mathrm{H}$ interactions between rings C and D with Ile205 and Arg239, respectively, in addition to the same interaction between OMe group at ring D and Phe300.

Figure $2 \mathrm{~B}$ showed $\pi-\mathrm{H}$ interactions between imidazole ring and Met7 and Lys4, while ring B revealed the same interaction with Me11 and Arg 5. The phenyl group (ring D) presented a $\pi-\mathrm{H}$ interaction with Met11, in addition to aliphatic hydrophobic action between nitro group and Lys4. Figure 2 (C) demonstrated that compound $\mathbf{5 m}$ was able to show $\pi-\pi$ interactions between imidazole ring and $\operatorname{Trp} 718$ as well as ring $D$ with Phe764. Further $\pi-\mathrm{H}$ and aliphatic hydrophobic interactions with protein receptors-binding residues including His714, Val715, Pro682, Ala748, Met749, Arg752, Met745, Leu707, Leu873 and Met742 were witnessed. 
Table 1. In vitro cytotoxicity ${ }^{\mathrm{a}}$ of some 4-nitroimidazole analogues given as $\mathrm{IC}_{50}{ }^{\mathrm{b}}$ in $\mu \mathrm{g} / \mathrm{mL}$

\begin{tabular}{lllll}
\hline Compd. & \multicolumn{4}{c}{ Cell line } \\
& MCF-7 & MDA MB231 & PC3 & Du145 \\
\hline $\mathbf{5 a}$ & $7.0 \pm 0.2$ & $>100$ & $48.0 \pm 0.6$ & $>100$ \\
$\mathbf{5 b}$ & $8.0 \pm 0.26$ & $24.88 \pm 1.92$ & $>100$ & $>100$ \\
$\mathbf{5 c}$ & $6.0 \pm 0.1$ & $40.23 \pm 4.79$ & $>100$ & $>100$ \\
$\mathbf{5 d}$ & $5.0 \pm 0.7$ & $18.68 \pm 1.03$ & $4.0 \pm 0.2$ & $>100$ \\
$\mathbf{5 e}$ & $5.0 \pm 0.17$ & $25.11 \pm 3.55$ & $44.0 \pm 8.3$ & $>100$ \\
$\mathbf{5 f}$ & $1.0 \pm 0$ & $20.12 \pm 1.55$ & $18.0 \pm 0.6$ & $>100$ \\
$\mathbf{5 g}$ & $>100$ & $20.72 \pm 1.91$ & $17.0 \pm 0.2$ & $>100$ \\
$\mathbf{5 h}$ & $2.0 \pm 0.1$ & $21.68 \pm 0.76$ & $>100$ & $>100$ \\
$\mathbf{5 i}$ & $5.0 \pm 0.17$ & $25.09 \pm 2.20$ & $6.0 \pm 0.1$ & $>100$ \\
$\mathbf{5 j}$ & $>100$ & $>100$ & $>100$ & $>100$ \\
$\mathbf{5 k}$ & $1.0 \pm 0$ & $12.02 \pm 1.25$ & $58.0 \pm 1.6$ & $>100$ \\
$\mathbf{5 l}$ & $2.0 \pm 0.1$ & $40.18 \pm 1.42$ & $>100$ & $>100$ \\
$\mathbf{5 m}$ & $4.0 \pm 0.1$ & $10.83 \pm 2.58$ & $41.0 \pm 0.9$ & $5.0 \pm 0.3$ \\
$\mathbf{5 n}$ & $2.0 \pm 0.1$ & $18.46 \pm 1.58$ & $73 \pm 1.0$ & $>100$ \\
$\mathbf{5 0}$ & $>100$ & $23.38 \pm 2.38$ & $>100$ & $>100$ \\
$\mathbf{5 p}$ & $2.0 \pm 0.1$ & $\mathrm{NT}$ & $>100$ & $>100$ \\
$\mathbf{5 q}$ & $>100$ & $>100$ & $>100$ & $>100$ \\
$\mathbf{5 r}$ & $>100$ & $13.72 \pm 2.59$ & $79.0 \pm 0.6$ & $>100$ \\
Paclitaxil & 0.021 & 0.0310 & 0.010 & 0.07 \\
Docitaxil & 0.230 & 0.105 & 0.010 & 0.1 \\
\hline & & & &
\end{tabular}

NT: Not tested. ${ }^{a}$ Cytotoxicity as $I_{50}$ ( \pm SD values) for each cell line is the concentration of tested compound with reduced by $50 \%$ the optical density of treated cells with respect to untreated cells using the MTT assay. ${ }^{b}$ Data represent the mean values of three independent determinations. 

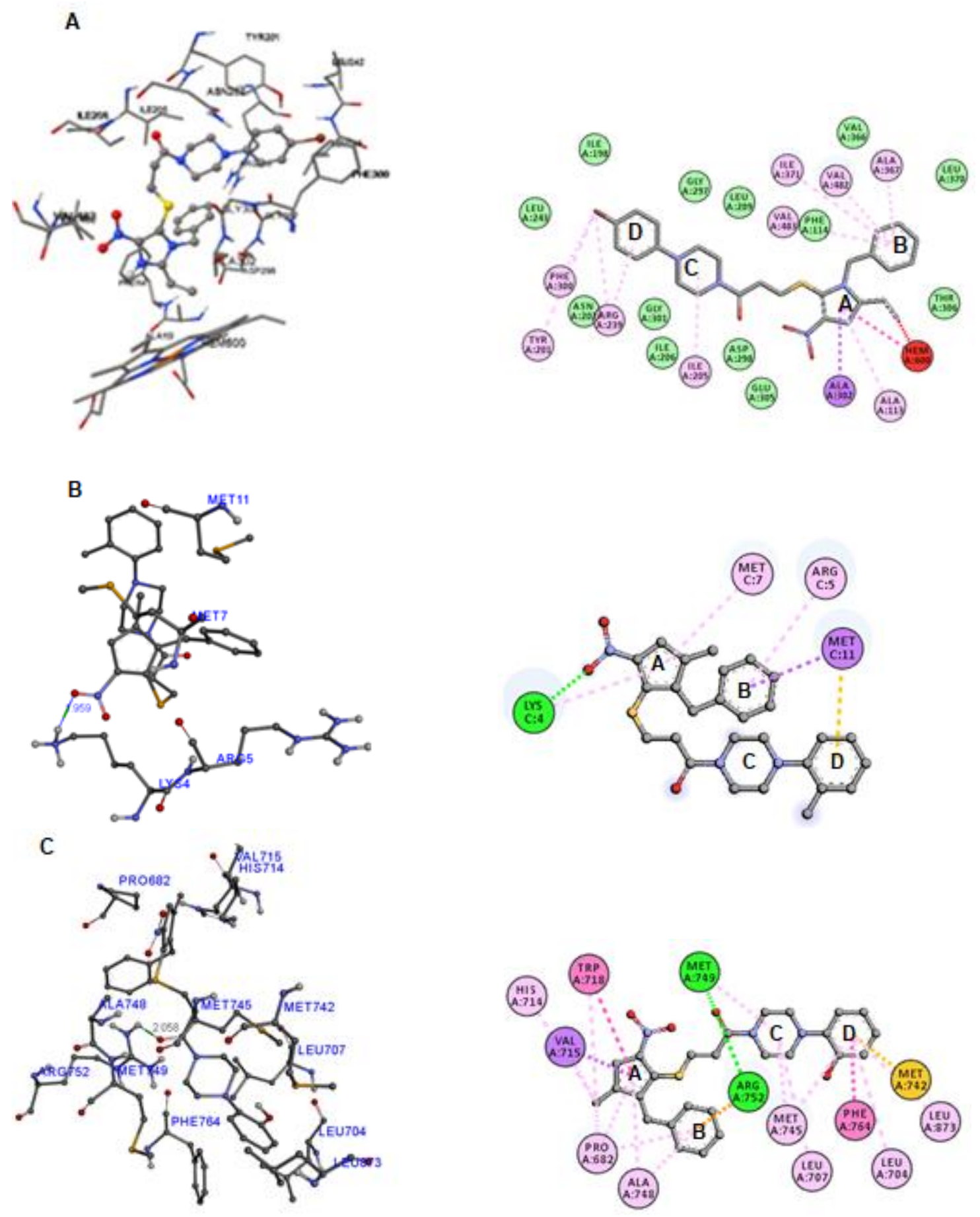

Figure 2. The interactions mode of compounds $5 d(A)$ and $5 f(B)$ and $5 m(C)$ with the active site amino acids of the proteins (PDB ID's: 3RUK, 3U2B and 5T8E), respectively.

\section{Conclusions}

In conclusion, we have reported the synthesis of new 4-nitroimidazole derived substituted arylpiperazine at C5. The structures of the new synthesized 4-nitroimidazole derivatives were confirmed by the spectral and mass data. The synthesized compounds were evaluated for their activity against breast cancer (MCF-7 and MDA MB231) and prostate cancer (PC3 and DU145) cell lines. Two derivatives, $\mathbf{5} f$ and $\mathbf{5 h}$ exhibited significant 
cytotoxic activity on MCF cell lines ( $\left(\mathrm{C}_{50} 1.0 \mu \mathrm{g} / \mathrm{mL}\right.$ ), while compounds $\mathbf{5 d}$ and $\mathbf{5 m}$ showed cytotoxic effect on PC3 and DU145 cell lines with $\mathrm{IC}_{50}$ values of 4.0 and $5.0 \mu \mathrm{g} / \mathrm{mL}$, respectively. These studies revealed that such molecules have high scope and potential for further investigations. Molecular docking studies were in agreement with the anticancer activity data. Studies on extensive diversification, mechanistic analysis and application of pharmacognosy principles, especially compounds $\mathbf{5 f}$ and $\mathbf{5 h}$, are currently under process to come up with better leads.

\section{Experimental Section}

General. Melting points were measured on a Mettler FP1 melting point apparatus and are uncorrected. Reaction progress was monitored by thin layer chromatography (TLC) on Alugram SIL G UV254 (MachereyNagel). All new compounds were analyzed for $\mathrm{C}, \mathrm{H}$, and $\mathrm{N}$ using a $2400 \mathrm{CHN}$ Elemental Analyzer by Perkin Elmer. The observed results agreed with the calculated percentages to within $\pm 0.4 \%$. ${ }^{1} \mathrm{H}$ and ${ }^{13} \mathrm{C}$-NMR spectra were recorded on a Bruker DRX-300 instrument. Chemical shifts are given in parts per million (ppm), and tetramethylsilane (TMS) was used as internal standard for spectra obtained in $\mathrm{CDCl}_{3}$. Mass spectra were measured on LC-MS 8050 triple quadrupole mass spectrometer (Shimadzu, Kyoto, Japan) equipped with a binary solvent delivery system (LC-30AD), a controller (CBM 20A), an autosampler (SIL-30A), column thermostat (CTO-20AC).

Synthesis of 3-(1-benzyl-2-ethyl-4-nitro-1H-imidazol-5-ylsulfanyl)propionyl chloride (4). A solution of 3 (0.5 $\mathrm{mmol}$ ) and thionyl chloride $(5 \mathrm{~mL})$ was heated under reflux at $75-80{ }^{\circ} \mathrm{C}$ for $3-4 \mathrm{~h}$. Excess of thionyl chloride was removed under vacuum to afford compound $\mathbf{4}$. The crude product 4 was used directly for the next step without further purification.

General procedure for the preparation of 4-nitroimidazole analogues (5a-p). Compound 4 (0.5 mmol) was dissolved in $\mathrm{CHCl}_{3}(15 \mathrm{~mL})$, piperazine derivatives $(0.7 \mathrm{mmol})$ and three drops of pyridine were added, the reaction mixture was stirred at room temperature for $18 \mathrm{~h}$. After cooling, the mixture was evaporated to dryness. The residue was partitioned between $\mathrm{CHCl}_{3}(50 \mathrm{~mL})$ and water $(50 \mathrm{~mL})$ and the combined organic extracts were dried over anhydrous sodium sulfate $\left(\mathrm{Na}_{2} \mathrm{SO}_{4}\right)$, filtered and evaporated to dryness. The residue was purified by thin-layer chromatography (TLC) and eluted with $\left(\mathrm{CHCl}_{3}-\mathrm{MeOH} ; 9.5: 0.5\right)$ to give 5a-p.

3-(1-Benzyl-2-ethyl-4-nitro-1H-imidazol-5-ylsulfanyl)-1-(4-phenyl-piperazin-1-yl)-propan-1-one (5a). Brown amorphous; Yield: (166 mg, 70\%). ${ }^{1} \mathrm{H}$ NMR (300 MHz, DMSO- $\left.d_{6}\right): \delta_{\mathrm{H}} 1.13\left(\mathrm{t}, J 7.3 \mathrm{~Hz}, 3 \mathrm{H}, \mathrm{CH}_{3} \mathrm{CH}_{2}\right), 2.64(\mathrm{~m}, 2 \mathrm{H}$,

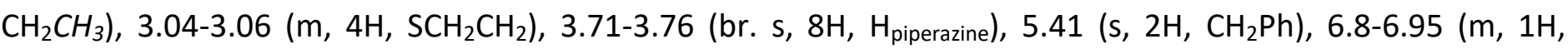

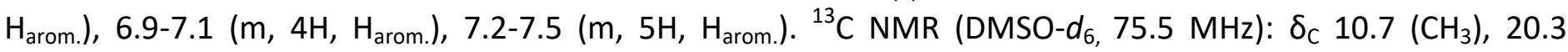
$\left(\mathrm{CH}_{2} \mathrm{CH}_{3}\right), 31.8\left(\mathrm{CH}_{2} \mathrm{CO}\right), 32.6\left(\mathrm{CH}_{2} \mathrm{~S}\right), 40.8,44.3,47.0,48.2$ (C piperazine), $48.5\left(\mathrm{CH}_{2} \mathrm{Ph}\right), 115.8,119.3,126.1,127.7$, 128.9, 129.0 (C arom.), 135.8 (C-5), 148.0 (C-4), 150.7 (C-2), 168.5 (C=O). LCM-MS (m/z): 480 [M+H] ${ }^{+}$. Anal. Calcd. for $\mathrm{C}_{25} \mathrm{H}_{29} \mathrm{~N}_{5} \mathrm{O}_{3} \mathrm{~S}: \mathrm{C}, 62.61 ; \mathrm{H}, 6.10 ; \mathrm{N}, 14.60$. Found: $\mathrm{C}, 62.85 ; \mathrm{H}, 6.30 ; \mathrm{N}, 14.83$.

\section{3-(1-Benzyl-2-ethyl-4-nitro-1H-imidazol-5-ylsulfanyl)-1-[4-(2-fluoro-phenyl)-piperazin-1-yl]-propan-1-one}

(5b). Brown amorphous; Yield: (340 mg, 71\%). ${ }^{1} \mathrm{H}$ NMR (300 MHz, DMSO- $\left.d_{6}\right): \delta_{\mathrm{H}} 1.14\left(\mathrm{t}, J 7.3 \mathrm{~Hz}, 3 \mathrm{H}, \mathrm{CH}_{3}\right)$, 2.57-2.65 (m, $\left.4 \mathrm{H}, \mathrm{CH}_{2} \mathrm{CH}_{3}+\mathrm{CH}_{2} \mathrm{CO}\right), 288-2.92\left(\mathrm{~m}, 4 \mathrm{H}, \mathrm{CH}_{2} \mathrm{~S}+2 \mathrm{H}_{\text {piperazine }}\right), 3.07$ (t, J $\left.6.3 \mathrm{~Hz}, 2 \mathrm{H}, \mathrm{H}_{\text {piperazine }}\right), 3.43-3.54$ $\left(\mathrm{m}, 4 \mathrm{H}, \mathrm{H}_{\text {piperazine }}\right), 5.40\left(\mathrm{~s}, 2 \mathrm{H}, \mathrm{CH}_{2} \mathrm{Ph}\right), 6.99-7.18\left(\mathrm{~m}, 6 \mathrm{H}, \mathrm{H}_{\text {arom. }}\right), 7.30-7.39\left(\mathrm{~m}, 3 \mathrm{H}, \mathrm{H}_{\text {arom }}\right) .{ }^{13} \mathrm{C}$ NMR (DMSO-d $d_{6}$ $75.5 \mathrm{MHz}): \delta_{\mathrm{C}} 10.7\left(\mathrm{CH}_{3}\right), 20.3\left(\mathrm{CH}_{2} \mathrm{CH}_{3}\right), 31.8\left(\mathrm{CH}_{2} \mathrm{CO}\right), 32.6\left(\mathrm{CH}_{2} \mathrm{~S}\right), 41.1,44.62,47.0,50.0\left(\mathrm{C}_{\text {piperazine }}\right), 50.2$ $\left(\mathrm{CH}_{2} \mathrm{Ph}\right), 115.5$ (d, $\left.{ }^{2} J_{\mathrm{CF}} 20.4, \mathrm{C}-3\right), 116.1,119.5,124.9,125.7,126.1,127.7$ (C arom.), $122.8\left(\mathrm{~d},{ }^{4} J_{\mathrm{CF}} 8.06, \mathrm{C}-5\right), 128.9$ (C-5), 135.9 (C-4), 139.5 (d, $\left.{ }^{3} J_{C F} 8.3, C-6\right), 150.0$ (C-2), 154.9 (d, J JF 244, C-2), 168.5 (C=O). LCM-MS (m/z): 498 
$[\mathrm{M}+\mathrm{H}]^{+}$. Anal. Calcd. for $\mathrm{C}_{25} \mathrm{H}_{28} \mathrm{FN}_{5} \mathrm{O}_{3} \mathrm{~S}: \mathrm{C}, 60.35 ; \mathrm{H}, 5.67 ; \mathrm{N}, 14.07$. Found: $\mathrm{C}, 60.56 ; \mathrm{H}, 5.79 ; \mathrm{N}, 14.22$. 3-(1-Benzyl-2-ethyl-4-nitro-1H-imidazol-5-ylsulfanyl)-1-[4-(4-fluoro-phenyl)-piperazin-1-yl]-propan-1-one (5c). Brown amorphous; Yield: (180 mg, 72\%). ${ }^{1} \mathrm{H}$ NMR (300 MHz, DMSO- $\left.d_{6}\right): \delta_{\mathrm{H}} 1.13\left(\mathrm{t}, J 7.3 \mathrm{~Hz}, 3 \mathrm{H}, \mathrm{CH}_{3}\right), 2.64-$ $2.66\left(\mathrm{~m}, 4 \mathrm{H}, \mathrm{CH}_{2} \mathrm{CH}_{3}+\mathrm{CH}_{2} \mathrm{CO}\right), 2.90-2.95\left(\mathrm{~m}, 6 \mathrm{H}, \mathrm{CH}_{2} \mathrm{~S}+\mathrm{H}_{\text {piperazine }}\right), 3.64-3.7\left(\mathrm{~m}, 4 \mathrm{H}, \mathrm{H}_{\text {piperazine }}\right), 5.40\left(\mathrm{~s}, 2 \mathrm{H}, \mathrm{CH}_{2} \mathrm{Ph}\right)$, 6.9-7.09 (m, 6H, $\left.\mathrm{H}_{\text {arom. }}\right), 7.31-7.34\left(\mathrm{~m}, 3 \mathrm{H}, \mathrm{H}_{\text {arom. }}\right) .{ }^{13} \mathrm{C}-\mathrm{NMR}$ (DMSO- $\left.d_{6}, 75.5 \mathrm{MHz}\right): \delta_{\mathrm{C}} 10.7\left(\mathrm{CH}_{3}\right), 20.3\left(\mathrm{CH}_{2} \mathrm{CH}_{3}\right)$, $31.8\left(\mathrm{CH}_{2} \mathrm{CO}\right), 32.6\left(\mathrm{CH}_{2} \mathrm{~S}\right), 40.9,44.4,47.0,49.0$ ( $\left.\mathrm{C}_{\text {piperazine }}\right), 49.3\left(\mathrm{CH}_{2} \mathrm{Ph}\right), 115.5,117.7,126.1,127.7,128.9$, 125.7, 135.9, 147.6, 148.0 ( $\left.\mathrm{C}_{\text {arom. }}+\mathrm{C}-5\right), 150.0$ (C-4); 154.7 (C-2), 168.5 (C=O). LCM-MS (m/z): 498 [M+H] ${ }^{+}$. Anal. Calcd. for $\mathrm{C}_{25} \mathrm{H}_{28} \mathrm{FN}_{5} \mathrm{O}_{3} \mathrm{~S}: \mathrm{C}, 60.35 ; \mathrm{H}, 5.67 ; \mathrm{N}, 14.07$. Found: $\mathrm{C}, 60.49 ; \mathrm{H}, 5.80 ; \mathrm{N}, 14.30$.

\section{3-(1-Benzyl-2-ethyl-5-nitro-1H-imidazol-5-ylsulfanyl)-1-[4-(4-chloro-phenyl)-piperazin-1-yl]-propan-1-one}

(5d). Reddish brown powder; Yield: (193 mg, 75\%); mp 84-87 ${ }^{\circ} \mathrm{C} .{ }^{1} \mathrm{H}$ NMR (300 MHz, DMSO- $\left.d_{6}\right): \delta_{H} 1.13$ (t, J 7.3 $\left.\mathrm{Hz}, 3 \mathrm{H}, \mathrm{CH}_{3}\right), 2.57-2.91\left(\mathrm{~m}, 6 \mathrm{H}, \mathrm{CH}_{2} \mathrm{CH}_{3}+\mathrm{SCH}_{2} \mathrm{CH}_{2}\right), 2.99-3.25\left(\mathrm{~m}, 6 \mathrm{H}, \mathrm{H}_{\text {piperazine }}\right), 3.42-3.69\left(\mathrm{~m}, 2 \mathrm{H}, \mathrm{H}_{\text {piperazine }}\right)$, $5.40\left(\mathrm{~s}, 2 \mathrm{H}, \mathrm{CH}_{2} \mathrm{Ph}\right), 6.94-7.13\left(\mathrm{~m}, 4 \mathrm{H}, \mathrm{H}_{\text {arom. }}\right), 7.23-7.45\left(\mathrm{~m}, 5 \mathrm{H}, \mathrm{H}_{\text {arom. }}\right) .{ }^{13} \mathrm{C} \mathrm{NMR}\left(\mathrm{DMSO}-d_{6}, 75.5 \mathrm{MHz}\right): \delta_{\mathrm{C}} 10.7$ $\left(\mathrm{CH}_{3}\right), 20.3\left(\mathrm{CH}_{2} \mathrm{CH}_{3}\right), 31.8\left(\mathrm{CH}_{2} \mathrm{CO}\right), 32.6\left(\mathrm{CH}_{2} \mathrm{~S}\right), 40.7,44.2,47.0,47.9\left(\mathrm{C}_{\text {piperazine }}\right), 48.2\left(\mathrm{CH}_{2} \mathrm{Ph}\right), 117.2,122.8$, 125.7, 126.1, 127.7, 128.6, 128.9, 129.0 (C arom.), 135.9 (C-5), 149.5 (C-4), 150.0 (C-2), 168.5 (C=O). LCM-MS $(\mathrm{m} / \mathrm{z}): 514 / 516[\mathrm{M}+\mathrm{H}]^{+}$. Anal. Calcd. for $\mathrm{C}_{25} \mathrm{H}_{28} \mathrm{ClN}_{5} \mathrm{O}_{3} \mathrm{~S}: \mathrm{C}, 58.41 ; \mathrm{H}, 5.49 ; \mathrm{N}, 13.62$. Found: $\mathrm{C}, 58.59 ; \mathrm{H}, 5.60 ; \mathrm{N}$, 13.85 .

\section{3-(1-Benzyl-2-ethyl-4-nitro-1H-imidazol-5-ylsulfanyl)-1-[4-(4-bromo-phenyl)-piperazin-1-yl]-propan-1-one}

(5e). Brown powder; Yield: (215 mg, 77\%); mp 85-88 ${ }^{\circ} \mathrm{C} .{ }^{1} \mathrm{H}$ NMR $\left(300 \mathrm{MHz}, \mathrm{DMSO}-d_{6}\right): \delta_{\mathrm{H}} 1.13(\mathrm{t}, J 7.3 \mathrm{~Hz}, 3 \mathrm{H}$, $\left.\mathrm{CH}_{3}\right), 2.57-2.88\left(\mathrm{~m}, 6 \mathrm{H}, \mathrm{CH}_{2} \mathrm{CH}_{3}+\mathrm{SCH}_{2} \mathrm{CH}_{2}\right) ; 2.9-3.27\left(\mathrm{~m}, 6 \mathrm{H}, \mathrm{H}_{\text {piperazine }}\right), 3.3-3.9\left(\mathrm{~m}, 2 \mathrm{H}, \mathrm{H}_{\text {piperazine }}\right), 5.40(\mathrm{~s}, 2 \mathrm{H}$, $\left.\mathrm{CH}_{2} \mathrm{Ph}\right), 6.86-6.91\left(\mathrm{~m}, 2 \mathrm{H}, \mathrm{H}_{\text {arom. }}\right), 7.00-7.06\left(\mathrm{~m}, 2 \mathrm{H}, \mathrm{H}_{\text {arom. }}\right), 7.30-7.34\left(\mathrm{~m}, 5 \mathrm{H}, \mathrm{H}_{\text {arom. }}\right) .{ }^{13} \mathrm{C}$ NMR (DMSO-d, 75.5 $\mathrm{MHz}): \delta_{\mathrm{C}} 10.4\left(\mathrm{CH}_{3}\right), 20.0\left(\mathrm{CH}_{2} \mathrm{CH}_{3}\right), 31.6\left(\mathrm{CH}_{2} \mathrm{CO}\right), 32.4\left(\mathrm{CH}_{2} \mathrm{~S}\right), 40.41,43.88,46.7,47.5\left(\mathrm{C}_{\text {piperazine }}\right), 47.8\left(\mathrm{CH}_{2} \mathrm{Ph}\right)$, 117.4, 122.7, 125.7, 126.1, 127.7, 128.6, 131.2, 135.9, 148.0 (C $\left.C_{\text {arom. }}+\mathrm{C}-5\right), 149.8$ (C-4), 150.0 (C-2), 168.5 (C=O). LCM-MS (m/z): 558/560 [M+H] $]^{+}$. Anal. Calcd. for $\mathrm{C}_{25} \mathrm{H}_{28} \mathrm{BrN}_{5} \mathrm{O}{ }_{3} \mathrm{~S}: \mathrm{C}, 53.77 ; \mathrm{H}, 5.05 ; \mathrm{N}, 14.31$. Found: $\mathrm{C}, 53.99 ; \mathrm{H}$, $5.18 ; \mathrm{N}, 14.58$.

3-(1-Benzyl-2-ethyl-4-nitro-1H-imidazol-5-ylsulfanyl)-1-(4-o-tolyl-piperazin-1-yl)-propan-1-one (5f). Brown powder; Yield: (183 mg, 74\%); mp 95-98 ${ }^{\circ} \mathrm{C} .{ }^{1} \mathrm{H}$ NMR $\left(300 \mathrm{MHz}, \mathrm{DMSO}-d_{6}\right): \delta_{\mathrm{H}} 1.13\left(\mathrm{t}, J 7.3 \mathrm{~Hz} ; 3 \mathrm{H}, \mathrm{CH}_{3}\right), 2.25(\mathrm{~s}$, $\left.3 \mathrm{H}, \mathrm{CH}_{3} \mathrm{Ph}\right), 2.59-2.92\left(\mathrm{~m}, 10 \mathrm{H}, \mathrm{CH}_{2} \mathrm{CH}_{3}+\mathrm{SCH}_{2} \mathrm{CH}_{2}+\mathrm{H}_{\text {piperazine }}\right), 3.05-3.95\left(\mathrm{~m}, 4 \mathrm{H}, \mathrm{H}_{\text {piperazine }}\right), 5.43\left(\mathrm{~s}, 2 \mathrm{H}, \mathrm{CH}_{2} \mathrm{Ph}\right)$,

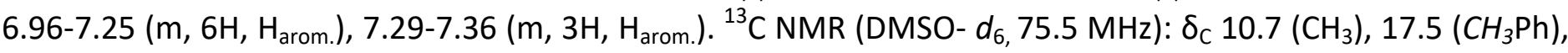
$20.3\left(\mathrm{CH}_{2} \mathrm{CH}_{3}\right), 31.9\left(\mathrm{CH}_{2} \mathrm{CO}\right), 32.7\left(\mathrm{CH}_{2} \mathrm{~S}\right), 41.6,45.0,47.0,51.2\left(\mathrm{C}_{\text {piperazine}}\right), 51.4\left(\mathrm{CH}_{2} \mathrm{Ph}\right), 118.9,123.2,125.8$, 126.1, 126.6, 127.7, 128.9, 130.8, 131.9, 135.9, 148 (C arom. $_{\text {a }}+$ - 5$), 150.0$ (C-4), 150.8 (C-2), 168.6 (C=O). LCM-MS $(\mathrm{m} / \mathrm{z}): 494[\mathrm{M}+\mathrm{H}]^{+}$. Anal. Calcd. for $\mathrm{C}_{26} \mathrm{H}_{31} \mathrm{~N}_{5} \mathrm{O}_{3} \mathrm{~S}: \mathrm{C}, 63.26 ; \mathrm{H}, 6.33 ; \mathrm{N}, 14.19$. Found: $\mathrm{C}, 63.45 ; \mathrm{H}, 6.25 ; \mathrm{N}, 14.34$.

3-(1-Benzyl-2-ethyl-4-nitro-1H-imidazol-5-ylsulfanyl)-1-(4-m-tolyl-piperazin-1-yl)-propan-1-one (5g). Brown amorphous; Yield: (169 mg, 68\%). ${ }^{1} \mathrm{H}$ NMR (300 MHz, DMSO-d $\left.d_{6}\right): \delta_{\mathrm{H}} 1.14\left(\mathrm{t}, J 7.3 \mathrm{~Hz}, 3 \mathrm{H}, \mathrm{CH}_{3} \mathrm{CH}_{2}\right), 2.25(\mathrm{~s}, 3 \mathrm{H}$,

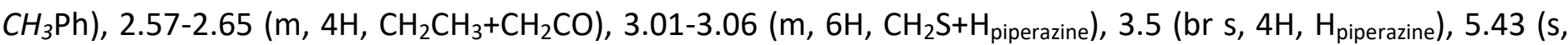
$\left.2 \mathrm{H}, \mathrm{CH}_{2} \mathrm{Ph}\right), 6.74-6.7\left(\mathrm{~m}, 3 \mathrm{H}, \mathrm{H}_{\text {arom. }}\right), 7.04-7.13\left(\mathrm{~m}, 3 \mathrm{H}, \mathrm{H}_{\text {arom. }}\right), 7.3\left(\mathrm{~m}, 3 \mathrm{H}, \mathrm{H}_{\text {arom. }}\right) .{ }^{13} \mathrm{C}$ NMR (DMSO-d, 75.5 $\mathrm{MHz}): \delta_{\mathrm{C}} 10.7\left(\mathrm{CH}_{3}\right), 20.3\left(\mathrm{CH}_{2} \mathrm{CH}_{3}\right), 21.4\left(\mathrm{CH}_{3} \mathrm{Ph}\right), 31.8\left(\mathrm{CH}_{2} \mathrm{CO}\right), 32.6\left(\mathrm{CH}_{2} \mathrm{~S}\right), 40.9,44.3,46.9,48.2\left(\mathrm{C}_{\text {piperazine }}\right)$, $48.6\left(\mathrm{CH}_{2} \mathrm{Ph}\right), 113.1,116.5,120.2,125.6,126.0,126.1,127.7,128.8,128.9,135.9\left(\mathrm{C}_{\text {arom. }}\right), 138.0$ (C-5), 150.0 (C4), $150.7(\mathrm{C}-2), 168.5(\mathrm{C}=\mathrm{O})$. LCM-MS $(\mathrm{m} / \mathrm{z})$ : $494[\mathrm{M}+\mathrm{H}]^{+}$. Anal. Calcd. for $\mathrm{C}_{26} \mathrm{H}_{31} \mathrm{~N}_{5} \mathrm{O} 3 \mathrm{~S}: \mathrm{C}, 63.26 ; \mathrm{H}, 6.33 ; \mathrm{N}$, 14.19. Found: $C, 63.49 ; \mathrm{H}, 6.35 ; \mathrm{N}, 14.44$.

\section{3-(1-Benzyl-2-ethyl-4-nitro-1H-imidazol-5-ylsulfanyl)-1-[4-(2-methoxy-phenyl)-piperazin-1-yl]-propan-1-one}

(5h). Brown powder; Yield: (178 mg, 70\%); mp 85-88 ${ }^{\circ} \mathrm{C} .{ }^{1} \mathrm{H}$ NMR $\left(300 \mathrm{MHz}, \mathrm{DMSO}-d_{6}\right): \delta_{\mathrm{H}} 1.13(\mathrm{t}, J 7.3 \mathrm{~Hz}, 3 \mathrm{H}$,

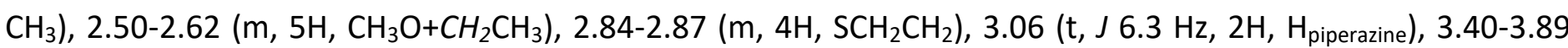
$\left(\mathrm{m}, 6 \mathrm{H}, \mathrm{H}_{\text {piperazine }}\right), 5.42\left(\mathrm{~s}, 2 \mathrm{H}, \mathrm{CH}_{2} \mathrm{Ph}\right), 3.87-7.06\left(\mathrm{~m}, 6 \mathrm{H}, \mathrm{H}_{\text {arom. }}\right), 7.36\left(\mathrm{~m}, 3 \mathrm{H}, \mathrm{H}_{\text {arom. }}\right) .{ }^{13} \mathrm{C}$ NMR (DMSO-d $6,75.5$ $\mathrm{MHz}): \delta_{\mathrm{C}} 10.7\left(\mathrm{CH}_{3}\right), 20.3\left(\mathrm{CH}_{2} \mathrm{CH}_{3}\right), 31.9\left(\mathrm{CH}_{2} \mathrm{CO}\right), 32.6\left(\mathrm{CH}_{2} \mathrm{~S}\right), 41.3,44.8,57.0,49.9\left(\mathrm{C}_{\text {piperazine }}\right), 50.3\left(\mathrm{CH}_{2} \mathrm{Ph}\right)$, 
$55.3\left(\mathrm{CH}_{3} \mathrm{O}\right), 111.7,118.2,120.8,123.0,125.8,126.1,127.7,128.9,130.0,135.9,140.6\left(\mathrm{C}_{\text {arom. }}+\mathrm{C}-5\right), 150.0(\mathrm{C}-$ 4), $151.9(\mathrm{C}-2), 168.5(\mathrm{C}=\mathrm{O})$. LCM-MS $(\mathrm{m} / \mathrm{z}): 510[\mathrm{M}+\mathrm{H}]^{+}$. Anal. Calcd. for $\mathrm{C}_{26} \mathrm{H}_{31} \mathrm{~N}_{5} \mathrm{O}_{4} \mathrm{~S}: \mathrm{C}, 61.28 ; \mathrm{H}, 6.13 ; \mathrm{N}$, 13.74. Found: $C, 61.47 ; H, 6.33 ; \mathrm{N}, 13.98$.

3-(1-Benzyl-2-ethyl-4-nitro-1H-imidazol-5-ylsulfanyl)-1-[4-(3-methoxy-phenyl)-piperazin-1-yl]-propan-1-one (5i). Brown powder; Yield: (190 mg, 75\%); mp 65-68 ${ }^{\circ} \mathrm{C} .{ }^{1} \mathrm{H}$ NMR (300 MHz, DMSO- $\left.d_{6}\right): \delta_{\mathrm{H}} 1.12(\mathrm{t}, J 7.3 \mathrm{~Hz}, 3 \mathrm{H}$, $\left.\mathrm{CH}_{3}\right)$, 2.50-2.66 (m, 5H, $\left.\mathrm{CH}_{3} \mathrm{O}+\mathrm{CH}_{2} \mathrm{CH}_{3}\right), 2.99-3.05\left(\mathrm{~m}, 4 \mathrm{H}, \mathrm{SCH}_{2} \mathrm{CH}_{2}\right), 3.51-3.73\left(\mathrm{~m}, 8 \mathrm{H}, \mathrm{H}_{\text {piperazine }}\right), 5.41(\mathrm{~s}, 2 \mathrm{H}$, $\mathrm{CH}_{2} \mathrm{Ph}$ ), 6.34-6.62 (m, 3H, $\left.\mathrm{H}_{\text {arom. }}\right), 7.0-7.2\left(\mathrm{~m}, 3 \mathrm{H}, \mathrm{H}_{\text {arom. }}\right), 7.25-7.54\left(\mathrm{~m}, 3 \mathrm{H}, \mathrm{H}_{\text {arom. }}\right) .{ }^{13} \mathrm{C} \mathrm{NMR}$ (DMSO- $d_{6,}, 75.5$ $\mathrm{MHz}): \delta_{\mathrm{C}} 10.7\left(\mathrm{CH}_{3}\right), 20.3\left(\mathrm{CH}_{2} \mathrm{CH}_{3}\right), 31.8\left(\mathrm{CH}_{2} \mathrm{CO}\right), 32.6\left(\mathrm{CH}_{2} \mathrm{~S}\right), 40.8,44.3,47.0,48.1\left(\mathrm{C}_{\text {piperazine }}\right), 48.4\left(\mathrm{CH}_{2} \mathrm{Ph}\right)$, $54.8\left(\mathrm{CH}_{3} \mathrm{O}\right), 101.9,104.6,107.7,108.4,125.7,126.1,127.7,128.9,129.7,135.8,150\left(\mathrm{C}_{\text {arom. }}+\mathrm{C}-5\right), 152.0(\mathrm{C}-4)$, 160.1 (C-2), 168.5 (C=O). LCM-MS (m/z): $510[\mathrm{M}+\mathrm{H}]^{+}$. Anal. Calcd. for $\mathrm{C}_{26} \mathrm{H}_{31} \mathrm{~N}_{5} \mathrm{O}_{4} \mathrm{~S}: \mathrm{C}, 61.28 ; \mathrm{H}, 6.13 ; \mathrm{N}, 13.74$. Found: $\mathrm{C}, 61.37 ; \mathrm{H}, 6.40 ; \mathrm{N}, 13.86$.

3-(1-Benzyl-2-ethyl-4-nitro-1H-imidazol-5-ylsulfanyl)-1-[4-(4-methoxy-phenyl)-piperazin-1-yl]-propan-1-one (5j). Brown amorphous; Yield: (176 mg, 69\%). ${ }^{1} \mathrm{H}$ NMR (300 MHz, DMSO- $\left.d_{6}\right): \delta_{\mathrm{H}} 1.12\left(\mathrm{t}, J 7.3 \mathrm{~Hz}, 3 \mathrm{H}, \mathrm{CH}_{3}\right), 2.56-$ $2.66\left(\mathrm{~m}, 4 \mathrm{H}, \mathrm{CH}_{2} \mathrm{CH}_{3}+\mathrm{CH}_{2} \mathrm{CO}\right), 2.83-3.2\left(\mathrm{~m}, 6 \mathrm{H}, \mathrm{CH}_{2} \mathrm{~S}+\mathrm{H}_{\text {piperazine }}\right), 3.2-3.9\left(\mathrm{~m}, 7 \mathrm{H}, \mathrm{CH}_{3} \mathrm{O}+\mathrm{H}_{\text {piperazine }}\right), 5.41(\mathrm{~s}, 2 \mathrm{H}$, $\left.\mathrm{CH}_{2} \mathrm{Ph}\right), 6.83-7.04\left(\mathrm{~m}, 6 \mathrm{H}, \mathrm{H}_{\text {arom. }}\right), 7.28-7.33\left(\mathrm{~m}, 3 \mathrm{H}, \mathrm{H}_{\text {arom. }}\right) .{ }^{13} \mathrm{C}$ NMR (DMSO-d, $\left.75.5 \mathrm{MHz}\right): \delta_{\mathrm{C}} 10.7\left(\mathrm{CH}_{3}\right), 20.3$ $\left(\mathrm{CH}_{2} \mathrm{CH}_{3}\right), 31.8\left(\mathrm{CH}_{2} \mathrm{CO}\right), 32.6\left(\mathrm{CH}_{2} \mathrm{~S}\right), 41.1,44.6,47.0,49.7\left(\mathrm{C}_{\text {piperazine }}\right), 50.0\left(\mathrm{CH}_{2} \mathrm{Ph}\right), 55.1\left(\mathrm{CH}_{3} \mathrm{O}\right), 114.5,118.0$, 126.7, 127.7, 128.9, 129.0, 135.8, 145.0, ( $\mathrm{C}_{\text {arom. }}+\mathrm{C}-5$ ), 148.0 (C-4), 153.3 (C-2), 168.5 (C=O). LCM-MS (m/z): 510 $[\mathrm{M}+\mathrm{H}]^{+}$. Anal. Calcd. for $\mathrm{C}_{26} \mathrm{H}_{31} \mathrm{~N}_{5} \mathrm{O}_{4} \mathrm{~S}: \mathrm{C}, 61.28 ; \mathrm{H}, 6.13 ; \mathrm{N}, 13.74$. Found: $\mathrm{C}, 61.33 ; \mathrm{H}, 6.29 ; \mathrm{N}, 14.01$.

3-(1-Benzyl-2-ethyl-4-nitro-1H-imidazol-5-ylsulfanyl)-1-[4-(2-hydroxy-phenyl)-piperazin-1-yl]-propan-1-one (5k). Brown powder; Yield: (186 mg, 75\%); mp 80-82 ${ }^{\circ} \mathrm{C} .{ }^{1} \mathrm{H}$ NMR (300 MHz, DMSO- $\left.d_{6}\right): \delta_{\mathrm{H}} 1.14(\mathrm{t}, J 7.3 \mathrm{~Hz}, 3 \mathrm{H}$, $\left.\mathrm{CH}_{3}\right), 2.69-2.74\left(\mathrm{~m}, 6 \mathrm{H}, \mathrm{CH}_{2} \mathrm{CH}_{3}+\mathrm{SCH}_{2} \mathrm{CH}_{2}\right), 2.81-2.85\left(\mathrm{~m}, 4 \mathrm{H}, \mathrm{H}_{\text {piperazine }}\right), 2.90-3.72(\mathrm{~m}, 4 \mathrm{H}, \mathrm{H}$ piperazine $), 5.40(\mathrm{~s}, 2 \mathrm{H}$, $\left.\mathrm{CH}_{2} \mathrm{Ph}\right), 6.71-6.93\left(\mathrm{~m}, 4 \mathrm{H}, \mathrm{H}_{\text {arom. }}\right), 7.00-7.10\left(\mathrm{~m}, 2 \mathrm{H}, \mathrm{H}_{\text {arom. }}\right), 7.28-7.30\left(\mathrm{~m}, 3 \mathrm{H}, \mathrm{H}_{\text {arom. }}\right) .{ }^{13} \mathrm{C} \mathrm{NMR}$ (DMSO-d $6,75.5$ $\mathrm{MHz}): \delta_{\mathrm{C}} 10.7\left(\mathrm{CH}_{3}\right), 20.3\left(\mathrm{CH}_{2} \mathrm{CH}_{3}\right), 31.9\left(\mathrm{CH}_{2} \mathrm{CO}\right), 32.6\left(\mathrm{CH}_{2} \mathrm{~S}\right), 41.3,44.9,47.0,50.0\left(\mathrm{C}_{\text {piperazine }}\right), 50.4\left(\mathrm{CH}_{2} \mathrm{Ph}\right)$, 115.6, 118.8, 119.4, 123.3, 126.1, 127.6, 128.8, 125.71, 129.0, (Carom.), 135.9 (C-5), 139.9 (C-4), 150.2 (C-2), $168.4(\mathrm{C}=\mathrm{O})$. LCM-MS (m/z): $496[\mathrm{M}+\mathrm{H}]^{+}$. Anal. Calcd. for $\mathrm{C}_{25} \mathrm{H}_{29} \mathrm{~N}_{5} \mathrm{O}{ }_{4} \mathrm{~S}: \mathrm{C}, 60.59 ; \mathrm{H}, 5.90 ; \mathrm{N}, 14.13$. Found: C, $60.78 ; \mathrm{H}, 6.02 ; \mathrm{N}, 14.28$.

\section{3-(1-Benzyl-2-ethyl-4-nitro-1H-imidazol-5-ylsulfanyl)-1-[4-(4-hydroxy-phenyl)-piperazin-1-yl]-propan-1-one}

(5I). Brown amorphous; Yield: (183 mg, 74\%). ${ }^{1} \mathrm{H}$ NMR (300 MHz, DMSO- $\left.d_{6}\right): \delta_{\mathrm{H}} 1.14\left(\mathrm{t}, J \mathrm{~J} .3 \mathrm{~Hz}, 3 \mathrm{H}, \mathrm{CH}_{3}\right), 2.68-$ $2.74\left(\mathrm{~m}, 6 \mathrm{H}, \mathrm{CH}_{2} \mathrm{CH}_{3}+\mathrm{SCH}_{2} \mathrm{CH}_{2}\right), 2.80-2.85\left(\mathrm{~m}, 4 \mathrm{H}, \mathrm{H}_{\text {piperazine}}\right), 2.90-3.72\left(\mathrm{~m}, 4 \mathrm{H}, \mathrm{H}_{\text {piperazine }}\right), 5.40\left(\mathrm{~s}, 2 \mathrm{H}, \mathrm{CH}_{2} \mathrm{Ph}\right)$, 6.71-6.93 (m, $\left.4 \mathrm{H}, \mathrm{H}_{\text {arom. }}\right)$, 7.09-7.12 (m, 2H, $\left.\mathrm{H}_{\text {arom. }}\right), 7.30-7.34\left(\mathrm{~m}, 3 \mathrm{H}, \mathrm{H}_{\text {arom. }}\right) .{ }^{13} \mathrm{C} \mathrm{NMR}\left(\mathrm{DMSO}-d_{6}, 75.5 \mathrm{MHz}\right): \delta_{\mathrm{c}}$ $10.7\left(\mathrm{CH}_{3}\right), 20.3\left(\mathrm{CH}_{2} \mathrm{CH}_{3}\right), 31.9\left(\mathrm{CH}_{2} \mathrm{CO}\right), 32.6\left(\mathrm{CH}_{2} \mathrm{~S}\right), 41.3,44.9,47.0,50.0\left(\mathrm{C}_{\text {piperazine }}\right), 50.4\left(\mathrm{CH}_{2} \mathrm{Ph}\right), 112.5$, 125.6, 125.7, 126.1, 127.7, 128.9, 135.9, 136.9, 148.0 ( $\left.\mathrm{C}_{\text {arom. }}+\mathrm{C}-5\right), 150.1$ (C-4), 154.2 (C-2), 168.4 (C=O). LCM$\mathrm{MS}(\mathrm{m} / z): 496[\mathrm{M}+\mathrm{H}]^{+}$. Anal. Calcd. for $\mathrm{C}_{25} \mathrm{H}_{29} \mathrm{~N}_{5} \mathrm{O}_{4} \mathrm{~S}: \mathrm{C}, 60.59 ; \mathrm{H}, 5.90 ; \mathrm{N}, 14.13$. Found: $\mathrm{C}, 60.81 ; \mathrm{H}, 5.99 ; \mathrm{N}$, 14.37.

2-\{4-[3-(1-Benzyl-2-ethyl-4-nitro-1H-imidazol-5-ylsulfanyl)-propionyl]-piperazin-1-yl\}-benzonitrile

$(5 \mathrm{~m})$. Brown amorphous; Yield: (190 mg, 75\%). ${ }^{1} \mathrm{H}$ NMR (300 MHz, DMSO- $\left.d_{6}\right): \delta_{\mathrm{H}} 1.15\left(\mathrm{t}, J \mathrm{~J} .3 \mathrm{~Hz}, 3 \mathrm{H}, \mathrm{CH}_{3}\right), 2.57-2.64$

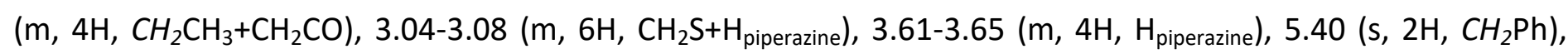
7.03-7.24 (m, $\left.4 \mathrm{H}, \mathrm{H}_{\text {arom. }}\right)$, 7.29-7.38 (m, 3H, $\left.\mathrm{H}_{\text {arom. }}\right)$, 7.59-7.79 (m, 2H, $\left.\mathrm{H}_{\text {arom. }}\right) .{ }^{13} \mathrm{C} \mathrm{NMR}\left(\mathrm{DMSO}-d_{6,}, 75.5 \mathrm{MHz}\right): \delta_{\mathrm{C}}$ $10.7\left(\mathrm{CH}_{3}\right), 20.3\left(\mathrm{CH}_{2} \mathrm{CH}_{3}\right), 31.3\left(\mathrm{CH}_{2} \mathrm{CO}\right), 32.7\left(\mathrm{CH}_{2} \mathrm{~S}\right), 41.1,44.6,46.9,50.7\left(\mathrm{C}_{\text {piperazine }}\right), 51.3\left(\mathrm{CH}_{2} \mathrm{Ph}\right), 104.9(\mathrm{CN})$, 118.0, 119.2, 122.4, 125.6, 126.0, 126.1, 127.6, 128.8, 134.1, 134.3 (Carom.), 135.8 (C-5), 150.0 (C-4), 154.8 (C2), $168.7(\mathrm{C}=\mathrm{O})$. LCM-MS (m/z): $505[\mathrm{M}+\mathrm{H}]^{+}$. Anal. Calcd. for $\mathrm{C}_{26} \mathrm{H}_{28} \mathrm{~N}_{6} \mathrm{O}_{3} \mathrm{~S}: \mathrm{C}, 61.89 ; \mathrm{H}, 5.59 ; \mathrm{N}, 16.65$. Found: $\mathrm{C}$, $62.03 ; \mathrm{H}, 5.71 ; \mathrm{N}, 16.89$. 
(m, 8H, $\left.\mathrm{CH}_{2} \mathrm{CH}_{3}+\mathrm{SCH}_{2} \mathrm{CH}_{2}+\mathrm{H}_{\text {piperazine }}\right), 2.99-3.88\left(\mathrm{~m}, 6 \mathrm{H}, \mathrm{H}_{\text {piperazine }}\right), 5.43\left(\mathrm{~s}, 2 \mathrm{H}, \mathrm{CH}_{2} \mathrm{Ph}\right), 7.03-7.06(\mathrm{~m}, 4 \mathrm{H}, \mathrm{H}$ arom.),

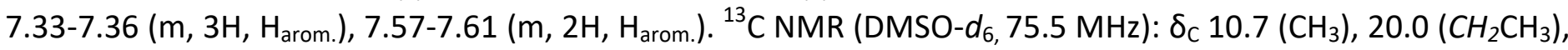

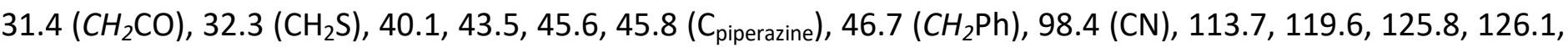
127.4, 128.6, 133.0, 135.9, 148.0 (C arom. + C-5), 149.7 (C-4), 152.7 (C-2), 168.6 (C=O). LCM-MS (m/z): 505 $[\mathrm{M}+\mathrm{H}]^{+}$. Anal. Calcd. for $\mathrm{C}_{26} \mathrm{H}_{28} \mathrm{~N}_{6} \mathrm{O}_{3} \mathrm{~S}: \mathrm{C}, 61.89 ; \mathrm{H}, 5.59 ; \mathrm{N}, 16.65$. Found: $\mathrm{C}, 62.11 ; \mathrm{H}, 5.48 ; \mathrm{N}, 16.91$.

\section{3-(1-Benzyl-2-ethyl-4-nitro-1H-imidazol-5-ylsulfanyl)-1-[4-(4-nitro-phenyl)-piperazin-1-yl]-propan-1-one}

(5o). Brown powder; Yield: (199 mg, 76\%); mp 96-98 ${ }^{\circ} \mathrm{C} .{ }^{1} \mathrm{H}$ NMR (300 MHz, DMSO- $\left.d_{6}\right): \delta_{\mathrm{H}} 1.14(\mathrm{t}, J 7.3 \mathrm{~Hz}, 3 \mathrm{H}$, $\left.\mathrm{CH}_{3}\right), 2.60-2.63\left(\mathrm{~m}, 6 \mathrm{H}, \mathrm{CH}_{2} \mathrm{CH}_{3}+\mathrm{SCH}_{2} \mathrm{CH}_{2}\right), 3.07$ (t, $\left.2 \mathrm{H}, J 6.2 \mathrm{~Hz}, \mathrm{H}_{\text {piperazine }}\right), 3.26-3.9\left(\mathrm{~m}, 6 \mathrm{H}, \mathrm{H}_{\text {piperazine }}\right), 5.40$ (s, $\left.2 \mathrm{H}, \mathrm{CH}_{2} \mathrm{Ph}\right), 6.93-7.14\left(\mathrm{~m}, 4 \mathrm{H}, \mathrm{H}_{\text {arom. }}\right), 7.26-7.46\left(\mathrm{~m}, 3 \mathrm{H}, \mathrm{H}_{\text {arom. }}\right), 8.0-8.014\left(\mathrm{~m}, 2 \mathrm{H}, \mathrm{H}_{\text {arom. }}\right) .{ }^{13} \mathrm{C}$ NMR (DMSO- $d_{6}$, $75.5 \mathrm{MHz}): \delta_{\mathrm{C}} 10.7\left(\mathrm{CH}_{3}\right), 20.3\left(\mathrm{CH}_{2} \mathrm{CH}_{3}\right), 31.7\left(\mathrm{CH}_{2} \mathrm{CO}\right), 32.6\left(\mathrm{CH}_{2} \mathrm{~S}\right), 40.4,43.6,45.7,45.8\left(\mathrm{C}_{\text {piperazine }}\right), 47.0$ $\left(\mathrm{CH}_{2} \mathrm{Ph}\right), 112.4,125.6,125.7,126.1,127.7,128.9,135.9,136.9,148.06$ (C $\left.\mathrm{arom}_{.+} \mathrm{C}-5\right), 150.0$ (C-4), 154.3 (C-2), $168.8(\mathrm{C}=\mathrm{O})$. LCM-MS (m/z): $525[\mathrm{M}+\mathrm{H}]^{+}$. Anal. Calcd. for $\mathrm{C}_{25} \mathrm{H}_{28} \mathrm{~N}_{6} \mathrm{O}{ }_{5} \mathrm{~S}: \mathrm{C}, 57.24 ; \mathrm{H}, 5.38 ; \mathrm{N}, 16.02$. Found: C, $57.41 ; \mathrm{H}, 5.44 ; \mathrm{N}, 16.27$.

\section{3-(1-Benzyl-2-ethyl-4-nitro-1H-imidazol-5-ylsulfanyl)-1-[4-(2-oxo-2-phenyl-ethyl)-piperazin-1-yl]-propan-1-} one (5p). Brown amorphous; Yield: (185 mg, 71\%). ${ }^{1} \mathrm{H}$ NMR (300 MHz, DMSO-d $\left.)_{6}\right): \delta_{\mathrm{H}} 1.14\left(\mathrm{t}, J 7.3 \mathrm{~Hz}, 3 \mathrm{H}, \mathrm{CH}_{3}\right)$, 2.17-2.86 (m, $\left.11 \mathrm{H}, \mathrm{CH}_{2} \mathrm{CH}_{3}+\mathrm{SCH}_{2} \mathrm{CH}_{2}+\mathrm{CH}_{3} \mathrm{CO}+\mathrm{H}_{\text {piperazine }}\right), 2.89-4.01\left(\mathrm{~m}, 6 \mathrm{H}, \mathrm{H}_{\text {piperazine }}\right), 5.43\left(\mathrm{~s}, 2 \mathrm{H}, \mathrm{CH}_{2} \mathrm{Ph}\right), 6.84-$ $7.15\left(\mathrm{~m}, 4 \mathrm{H}, \mathrm{H}_{\text {arom. }}\right), 7.16-7.68\left(\mathrm{~m}, 3 \mathrm{H}, \mathrm{H}_{\text {arom. }}\right), 7.7-8.14\left(\mathrm{~m}, 2 \mathrm{H}, \mathrm{H}_{\text {arom. }}\right) .{ }^{13} \mathrm{C} \mathrm{NMR}\left(\mathrm{DMSO}-d_{6}, 75.5 \mathrm{MHz}\right): \delta_{\mathrm{C}} 10.7$ $\left(\mathrm{CH}_{3}\right), 20.3\left(\mathrm{CH}_{2} \mathrm{CH}_{3}\right), 26.1\left(\mathrm{CH}_{3} \mathrm{CO}\right), 31.8\left(\mathrm{CH}_{2} \mathrm{CO}\right), 32.7\left(\mathrm{CH}_{2} \mathrm{~S}\right), 40.6,43.9,46.2,46.5\left(\mathrm{C}_{\text {piperazine }}\right), 47.0\left(\mathrm{CH}_{2} \mathrm{Ph}\right)$, 113.2, 125.6, 126.1, 126.8, 127.7, 128.9, 129.0, 130.1 (C arom.), 135.9 (C-5), 150.0 (C-4), 153.4 (C-2), 168.7 $(\mathrm{NC}=\mathrm{O}), 195.6(\mathrm{PhC}=\mathrm{O})$. LCM-MS $(\mathrm{m} / \mathrm{z}): 522[\mathrm{M}+\mathrm{H}]^{+}$. Anal. Calcd. for $\mathrm{C}_{27} \mathrm{H}_{31} \mathrm{~N}_{5} \mathrm{O}_{4} \mathrm{~S}: \mathrm{C}, 62.17 ; \mathrm{H}, 5.99 ; \mathrm{N}, 13.43$. Found: $\mathrm{C}, 62.35 ; \mathrm{H}, 6.11 ; \mathrm{N}, 13.60$.

3-(1-Benzyl-2-ethyl-4-nitro-1H-imidazol-5-ylsulfanyl)-1-(4-methyl-piperazin-1-yl)-propan-1-one (5q). Yellow amorphous; Yield: (164 mg, 75\%). ${ }^{1} \mathrm{H}$ NMR (300 MHz, DMSO- $\left.d_{6}\right): \delta_{\mathrm{H}} 1.09-1.15\left(\mathrm{~m}, 6 \mathrm{H}, 2 \times \mathrm{CH}_{3}\right), 2.5-2.67(\mathrm{~m}, 10 \mathrm{H}$, $\left.\mathrm{CH}_{2} \mathrm{CH}_{3}+\mathrm{H}_{\text {piperazine }}\right), 3.04$ (t, J $6.3 \mathrm{~Hz}, 2 \mathrm{H}, \mathrm{CH}_{2} \mathrm{CO}$ ), 4.04 (t, J $7.0 \mathrm{~Hz}, 2 \mathrm{H}, \mathrm{CH}_{2} \mathrm{~S}$ ), 5.41 (s, 2H, CH $\mathrm{Ch}_{2} \mathrm{Ph}, 7.04$ (d, J=7.0

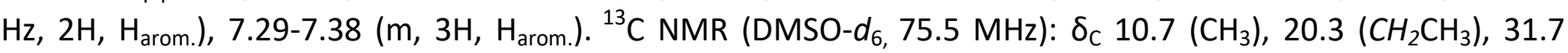
$\left(\mathrm{CH}_{2} \mathrm{CO}\right), 32.4\left(\mathrm{CH}_{2} \mathrm{~S}\right), 41.6,52.2$ ( $\left.\mathrm{C}_{\text {piperazine}}\right), 42.2\left(\mathrm{CH}_{3} \mathrm{~N}\right), 47.0\left(\mathrm{CH}_{2} \mathrm{Ph}.\right), 125.5,126.1,127.7,128.9$ ( $\left.\mathrm{C}_{\text {arom. }}\right), 135.8$ (C-5), 150.1 (C-2), 168.9 (C=O). LCM-MS (m/z): $418[\mathrm{M}+\mathrm{H}]^{+}$. Anal. Calcd. for $\mathrm{C}_{20} \mathrm{H}_{27} \mathrm{~N}_{5} \mathrm{O}{ }_{3} \mathrm{~S}: \mathrm{C}, 57.53 ; \mathrm{H}, 6.52 ; \mathrm{N}$, 16.77. Found: $\mathrm{C}, 57.75 ; \mathrm{H}, 6.61 ; \mathrm{N}, 16.93$.

4-[3-(1-Benzyl-2-ethyl-4-nitro-1H-imidazol-5-ylsulfanyl)-propionyl]-piperazine-1-carboxylic acid ethyl ester (5r). Brown amorphous; Yield: (168 mg, 71\%). ${ }^{1} \mathrm{H}$ NMR (300 MHz, DMSO- $\left.d_{6}\right): \delta_{\mathrm{H}} 1.10-1.13\left(\mathrm{~m}, 6 \mathrm{H}, 2 \times \mathrm{CH}_{3}\right), 2.50-$ $2.72\left(\mathrm{~m}, 10 \mathrm{H}, \mathrm{CH}_{2} \mathrm{CH}_{3}+\mathrm{H}_{\text {piperazine }}\right), 3.02-3.18\left(\mathrm{~m}, 4 \mathrm{H}, \mathrm{SCH}_{2} \mathrm{CH}_{2}\right), 5.42\left(\mathrm{~s}, 2 \mathrm{H}, \mathrm{CH}_{2} \mathrm{Ph}\right), 7.04$ (d, J 7.0 Hz, 2H, $\mathrm{H}_{\text {arom. }}$ ), 7.03-7.39 (m, 3H, Harom.). ${ }^{13} \mathrm{C}$ NMR (DMSO-d, $\left.75.5 \mathrm{MHz}\right): \delta_{\mathrm{C}} 10.7\left(\mathrm{CH}_{3}\right), 14.5\left(\mathrm{CH}_{3} \mathrm{CH}_{2} \mathrm{O}\right), 20.3\left(\mathrm{CH}_{3} \mathrm{CH}_{2} \mathrm{C}\right), 31.8$ $\left(\mathrm{CH}_{2} \mathrm{CO}\right), 32.7\left(\mathrm{CH}_{2} \mathrm{~S}\right), 40.8,42.9,43.2,44.3$ ( $\left.\mathrm{C}_{\text {piperazine}}\right), 47.0\left(\mathrm{CH}_{2} \mathrm{Ph}.\right), 60.9\left(\mathrm{CH}_{2} \mathrm{O}\right), 125.6,126.1,127.7,128.9$ (C arom.), 135.8 (C-4), 148.1 (C-5); 150.1 (C-2), 154.6, 168.7 (C=O). LCM-MS (m/z): 476 [M+H] ${ }^{+}$. Anal. Calcd. for $\mathrm{C}_{22} \mathrm{H}_{29} \mathrm{~N}_{5} \mathrm{O}_{5} \mathrm{~S}: \mathrm{C}, 55.56 ; \mathrm{H}, 6.15 ; \mathrm{N}, 14.73$. Found: $\mathrm{C}, 55.69 ; \mathrm{H}, 6.01 ; \mathrm{N}, 14.58$.

\section{Biological assays}

Cell Lines and Culture Conditions. Human breast adenocarcinoma MCF-7 (HTB-22TM), epithelial breast cancer MDA MB231, human androgen-resistant (PC-3) and androgen-sensitive (DU145) prostate cancer cell lines, cells were from the American Type Culture Collection (ATCC, Rockville, MD, USA). MCF-7 cells were cultured in DMEM. PC3, and DU145 cells were cultured in RPMI-1640 medium; media contained 10\% heat-inactivated fetal bovine serum (FBS), 1\% (v/v) of penicillin $(10,000$ units $/ \mathrm{mL})$-streptomycin $(10 \mathrm{mg} / \mathrm{mL})$, and $1 \%(\mathrm{v} / \mathrm{v}) \mathrm{L}-$ glutamine (200 mM) (all from Sigma-Aldrich). All cell lines were cultured at $37 \mathrm{OC}$ in a $5 \% \mathrm{CO}_{2}$, fully humidified atmosphere.

Cytotoxicity Assay. Cell lines were seeded in 96-well flat-bottomed microplates in $100 \mu \mathrm{L}$ culture medium at 
the following densities: MCF-7, MDA MB231, PC-3, and DU145 cells ( $3 \times 10^{3}$ cells/well). Cells were allowed to adhere for $24 \mathrm{~h}$. Then, the medium was replaced with fresh medium alone or with the tested compounds at increasing concentrations from 0 to $250 \mathrm{uM}$ for cancerous cell lines and to $500 \mathrm{uM}$ for the normal dermal fibroblast cells. The reference drugs cisplatin (0-100 uM) and doxorubicin (0-10 uM) were included as positive controls for growth inhibition. After $72 \mathrm{~h}$, cell viability was assayed using the 3-(4,5-dimethylthiazol-2-yl)-2,5diphenyltetrazolium bromide (MTT) assay [31]. All experimental conditions were tested in triplicate and the experiment was performed three times. Half maximal inhibitory concentrations $\left(\mathrm{IC}_{50}\right.$, the concentration required for $50 \%$ in vitro inhibition of growth) were calculated for each experiment using Graphpad prism software (Version 8, San Diego, CA, USA). IC 50 values were reported as mean \pm SD

\section{Dock and virtual screening}

Preparations of ligands and proteins. The structures of ligands $\mathbf{5 d}, \mathbf{5 f}$ and $\mathbf{5 m}$ were prepared by Avogadro ( $\mathrm{v}$. 1.0.1) ${ }^{33}$ software and saved as PDB file formate. Then, the two ligands were prepared selecting torsions and the structures were converted from PDB formate to PDBQT. The PDBQT files for the proteins and the ligands, united atom Kollman charges, fragmental volumes, and solvation parameters were performed by the MGLTools software. Ligand structures were energy minimized with the MMFF94 force field. The native ligands and crystallographic water molecules were removed from the PDB structures and the polar hydrogens were added before docking.

Grid map calculations. AutoDock grid maps were calculated for each compound using AutoGrid4, based on the active site coordinates of each protein crystal structure. The size of all grid boxes $60 \times 60 \times 60 \times y z$ points with a grid spacing of $0.375 \AA$. The grid center dimensions were $85.44,52.99$, and 46.41 for $x, y$ and $z$ respectively. Maps were calculated for each atom type in each ligand along with an electrostatic and desolavation map using dielectric value of -0.1465 .

Molecular docking simulations. Molecular docking simulations were undertaken using the Autodock program. ${ }^{32}$ Protein structures were prepared using UCSF Chimera $1.15 .^{34}$ In Autodock program, the Lamarkian Genetic Algorithm (LGA) was used for pose sampling and the number of energy simulations was set to 2500000. The default scoring function was used for calculating the docking scores. Autogrid was used to prepare the maps. The results of molecular docking were visualized in Biovia Discovery Studio 2020 software s $^{35}$ and then analyzing the docking results. All docking simulations performed to validate the method, using the ligands present in crystal structures, were able to reproduce the ligand-protein interaction geometries. The image of the native ligands for 3RUK, 3U2B and 5T8E against the redocked native ligand with AutoDock is shown in Figure 2, meanwhile the root-mean-square deviation of atomic positions (RMSD) was $0.405 \AA$.

\section{Acknowledgements}

Authors would like to thank the Scientific Research Support Fund / Ministry of Higher Education, Jordan (grant No. Bas $1 / 1 / 2017$ ) for providing necessary facilities and funds for conducting this research.

\section{Supplementary Material}

Supplementary material is attached 


\section{References}

1. Nay, B.; Schiavi, B.; Ahond, B.; Poupat, C.; Potier, P. Synthesis 2005, 1, 97. https://doi: 10.1055/s-2004-834907

2. Sharma, S.; Sharma, V.; Singh, G.; Kaur, H.; Srivastava, S.; Ishar, M. P. S. J. Chem. Biol. 2017, $10,35$. https://doi:10.1007/s12154-016-162-8

3. Liu, C.; Shi, C.; Mao, F.; Xu, Y.; Liu, J.; Wei, B.; Zhu, J.; Xiang, M.; Li, J. Molecules 2014,. 19, 15653. https://doi:10.3390/molecules191015653

4. Ulmschneider, S.; Vieira, U.; Mitrenga, M.; Hartmann, R.; Marchais, S.; Klein, C.; Bureik, M.; Bernhardt, R.; Antes, I.; Lengauer, T. J. Med. Chem. 2015, 48, 1796. https://doi:10.1021/jm049600p

5. Silvestri, R.; Artico, M.; Regina, G.; Pasqali, A.; Martion, G.; Auria, F.; Nencioni, L.; Palamara, T. J. Med. Chem. 2004, 47, 3924.

https://doi:10.1021/jm049856v

6. Akturk, Z.; Kilik, F.; Erol, K.; Pabuccoglu, V. ILFarmaco 2002, 57, 201.

https://doi:10.1016/S0014-827X(01)01197-1

7. Iradyan, M. A.; Iradyan, N. S.; Stepanyan, G. M.; Arsenyan, F. G.; Garibdzhanyan, B. T. Pharm. Chem. J. 2010, 44, 175.

\section{https://doi:10.0091-150x/10/4404-0175}

8. Davidov, D. J. IMAB, 2016, 22, 1036.

https://doi:10.5272/jimab.2016221.1036

9. Legha, S.; Ring, S.; Bedikian, A.; Plager, C.; Eton, O.; Buzaid, A. C.; Papadopoulos, N. Oncol. 1996, 7, 827. https://doi:10.1093/oxfordjournals.annonc.a010762

10. Ozdemir, N.; Dogan, M.; Sendur, M. A. N.; Yazici, O.; Abali, H.; Yazilitas, D.; Akinci, M. B.; Aksoy, S.; Zengin, N. Asian. Pac. J. Cancer Prev. 2014, 15, 8715.

\section{https://doi:10.7314/APJCP.2014.15.20.8715}

11. Brusamolino, E.; Baio, A.; Orlandi, E.; Arcaini, L.; Passamonti, F.; Griva, V.; Casagrande, W.; Pascutto, C.; Franchini, P.; Lazzarino, M. Clin. Cancer. Res. 2006, 12, 6487.

https://doi: 10.1158/1078-0432

12. Adkins, K. E.; Solimando, D. A.; Waddell, J. A. Hosp. Pharm. 2015, 50, 194.

https://doi:10.1310/hpj5003-194

13. Mrugala, M. M.; Adair, J.; Kiem, H-P. Drugs Today (Barc) 2010, 46, 833. https://doi:10.1358/dot.2010.46.11.1549024

14. Rønning, P. A.; Helseth, E.; Meling, T. R.; Johannesen, T. B. Neuro-Oncology , 2012, 14, 1178.

\section{https://doi:10.1093/neuonc/nos153}

15. Hashem, F. M.; Shaker, D. S.; Ghorab, M. K.; Nasr, M.; Ismail, A. AAPS Pharm. Sci. Tech. 2011, $12,879$. https://doi:10.1208/s12249-011-9653-7

16. Crowley, P. D.; Gallagher, H. C. J. Appl. Microbiol. 2014, 117, 611. https://doi:10.1111/jam.12554

17. Ceruelos, A. H.; Romero-Quezada, L. C.; Ledezma, J. C. R.; Contreras, L. L. Eur. Rev. Med. Pharmacol. Sci. 2019, 23, 397.

\section{https://doi:10.26355/eurrev 20190116788}

18. Meißner, R.; Feketeová, L.; Illenberger, E.; Denifl, S. Int. J. Mol. Sci. 2019, 20, 3496. https://doi:10.3390/ijms20143496

19. Beggs, W. H.; Andrews, F. A.; Sarosi, G. A. Life. Sci. 1981, 28, 111. 
20. Nyirjesy, P.; Schwebke, J.; Secnidazole, R. Future Microbiol. 2018, 13, 507. https://doi.org/10.2217/fmb-2017-0270

21. Thulkar, J.; Kriplani, A.; Agarwal, N. A. Indian J. Pharmacol. 2012, 44, 243.

\section{https://doi:10.4103/0253-7613.93859}

22. Al-Masoudi, N. A.; Al-Soud, Y. A.; De Clercqc, E.; Paneccoque, C. Antiviral Chem. Chemother. 2007, 18, 191.

https://doi:10.1177/095632020701800403

23. Al-Masoudi, N. A.; Al-Soud, Y. A.; Kalogerakis, A.; Pannecouque, C.; De Clercq, E. Chem. Biodivers. 2006, 3, 515 .

\section{https://doi:10.1002/cbdv.200690055}

24. Al-Masoudi, N. A.; Pfleiderer, W.; Pannecouque, C. Z. Naturforsch., B. J. Chem. Sci. 2012, $67,835$. https://doi:10.5560/ZNB.2012-0122

25. Al-Soud, Y. A.; Al-Masoudi, N. A. Synth. Commun. 2005, 35, 2259. https://doi:10.1080/00397910500184735

26. Al-Soud, Y. A.; Al-Masoudi, N. A.; Al-Suod, H. H.; Panneccoque, C. Z. Naturforsch., B: J. Chem. Sci. 2012, $67,925$.

\section{https://doi:10.5560/znb.2012-0185}

27. Al-Soud, Y. A.; Al-Masoudi, N. A.; De Clercqc, E.; Panneccoque, C. Heteroat. Chem. 2007, $18,333$. https://doi:10.1002/hc.20301

28. Al-Soud, Y. A.; Al-Masoudi, N. A.; Hassan, H. G.; De Clercqc, E.; Panneccoque, C. Acta Pharm. 2007, 57, 379.

\section{https://doi:10.2478/v10007-007-0031-7}

29. Al-Soud, Y. A.; Al-Sa'doni, H.; Amajaour, H. A. S.; Al-Masoudi, N. A. Z. Naturforsch., B. J. Chem. Sci. 2006, 62, 523.

\section{https://doi:10.1515/ znb-2007-0406}

30. Al-Qawasmeh, R. A.; Al-Soud, Y. A.; Alhelal, K. A. S.; Khanfar, M. A. Z. Kristallogr-New Cryst. Struct. 2020, 235, 751.

\section{https://doi:10.1515/ncrs-2020-0003}

31. Mosmann, T. J. Immunol. Methods 1993, 65, 55.

https://doi:10.1016/0022-1759(83)90303-4

32. Morris, G. M.; Huey, R.; Lindstrom, W.; Sanner, M. F.; Belew, R. K.; Goodsell, D. S.; Olson, A. J. J. Comput. Chem. 2009, 16, 2785.

https://doi:10.1002/jcc.21256

33. Hanwell, M. D.; Curtis, D. E.; Lonie, D. C.; Vandermeersch, T.; Zurek, E.; Hutchison, G. R. J. Cheminform. 2012, 4, 17.

\section{https://doi:10.1186/1758-2946-4-17}

34. Pettersen, E. F.; Goddard, T. D.; Huang, C. C.; Couch, G. S.; Greenblatt, D. M.; Meng, E. C.; Ferrin, T. E. J. Comput. Chem. 2004, 13, 1605.

https://doi:10.1002/jcc.20084

35. BIOvIA DS. Discovery studio modeling environment. San Diego, Dassault Systêmes, 2020. 